\title{
A Gift of Life: An Islamic Perspective in Organ Donation and Transplantation
}

\section{Shahid Athar}

Department of Endocrinology and Medicine, Indiana University School of Medicine, USA

*Corresponding author: Shahid Athar, MD, FACP, FACE, Clinical Associate Professor, Department of Medicine and Endocrinology, St. Vincent Hospital and Indiana University, School of Medicine Indianapolis 46260, Indiana, USA, Tel: 1-317-582-8900; E-mail: sathar3624@aol.com

Rec date: Dec 30, 2014, Acc date: Feb 25, 2015, Pub date: Feb 27, 2015

Copyright: (c) 2015 Athar S. This is an open-access article distributed under the terms of the Creative Commons Attribution License, which permits unrestricted use, distribution, and reproduction in any medium, provided the original author and source are credited.

\begin{abstract}
Organ Donation and Transplantation is an issue that has widespread ramifications. In addition to the medical/ technical aspects, there are legal, moral, ethical, economic, logistical and humanitarian aspects. Each of these aspects may have some peculiarity related to the donor and recipient. This paper deals primarily with the moral, ethical and humanitarian aspects of the issue. From the viewpoint of Islam, organ transplantation is an acceptable therapeutic value provided the following criteria are fulfilled:

1. There is no other equally effective therapeutic solution available that is simpler, safer and/or more cost effective.

2. The organ donation does not result in any harm to the donor

3. The organ donation is done with the free will and full approval of the donor, or in the case of an unconscious donor, or an organ donation taken from a cadaver, the approval of the next of kin or legal guardian.

4. In the case of the donation of a single organ upon which the life of the donor depends, e.g., the heart or liver, the organ may not be removed from the donor until the donor's brain stem death is ascertained.

5. The donated organ is a gift and is not sold.

6. If the transaction results in material or monetary gain to the donor or to the donor's family, the gain must not be in the form of price, but the donor or his/her family may accept a gift as a token of appreciation since the donated organ is considered a gift to the recipient.

7. The transplantation of active reproductive organs is categorically forbidden.

8. The basic rule governing the entire transaction is that organ transplantation is considered a humanitarian act of mercy accomplished with the free will and approval of all parties involved under no pressure, coercion or injustice.
\end{abstract}

Keywords: Organ donation and transplantation; Islamic medical ethics

\section{Review}

Our life is a gift that we humans must appreciate and share with others. Organ donation is sharing the much needed gift. The Islamic Holy Book Quran, encourages Muslims to save life by stating "Anyone who saves one life it is as if he has saved all mankind" [1]. In spite of such clear instructions, Muslims in general, educated or not are sometimes reluctant to sign up donor card, while themselves willing to receive organ for transplantation when needed. Their reluctance is not based on notion as held by some that one has to present to God in the Day of Judgment with all intact organs. "They ask who will revive the dead and rotten bones after death, tell them "He will give life to them who gave them in life in the first place [2]. Their reluctance based on definition of death (brain stem death verses cardio respiratory arrest, harvesting organs for transplantation, and cost of the procedure.

Currently according to US Bureau of Statistics 1, 23,175 people are on wait list to receive an organ transplant, out of which 1, 01,170 are kidney. 16, 896 transplants took place in 2013 out which 11,163 were kidney transplants. 3000 new applicants are added each year. 4,453
Americans died in 2013 while waiting to receive renal transplant (12/ day)

With the improvement of surgical techniques, the advances in the technology of organ preservation, and with the availability of better and safer drugs for prevention of tissue rejection, organ transplantation is now being done in an ever-increasing number for a growing number of organs with a rapidly improving success rate. As the demand increases for organs to be transplanted, the logistics of the entire issue become more complex. This paper deals primarily with moral, ethical ad humanitarian aspects of the issue. Although the technical and economic aspects of organ transplantation are not directly addressed in this paper, the author is by no means insensitive to the magnitude of the impact of these two aspects on the entire picture of global health care.

In Islam, it is a religious duty for the sick person to seek treatment: "O worshipers of God seek treatment" [3]. It becomes a collective duty to cooperate with each other and achieve this goal of treatment and /or healing. "Cooperate towards righteousness and God-consciousness..." [4] However, while cooperating toward the goal of treatment and/or healing, the believers have to be mindful of certain Islamic rules: 
1. While cooperating to do a good deed, we must not be involved in bad deeds or aggression: "...Do not cooperate toward bad deeds and aggression" [4].

2. We must not inflict harm on anyone, and must not allow harm to be inflicted on ourselves: "Do not cause harm and do not get hurt" [5].

3. Whenever we have a choice between two options leading to the same goal, we should always opt for the simpler and/or easier option: "Whenever the messenger of God was given a choice between two matters, he always elected the simpler and/or easier one [6].

4. We must not go to excesses and must not be wasteful. "Eat and drink, and do not waste indeed, He (God) does not love the wasteful ones." "The wasteful ones are companions of the devils" [7].

Applying the above listed rules means that, before transplantation is considered, any equally effective therapeutic modality that is simpler, safer and more cost effective must be first considered and given priority. In other words, if transplantation is considered indicated and justified (after satisfying all of the above listed rules), then transplantation must be considered a "fulfillment of Islamic duty" [8].

The statement that I mentioned earlier: "Any equally effective therapeutic modality that is simpler, safer and more cost effective" needs more explanation and elaboration. Modern western medicine has failed in offering a curative treatment for chronic illnesses. The evidence and proof of this failure is the chronicity of the illness. By definition, a chronic illness is an illness that has persisted for months or years. The fact that an illness is considered "chronic" and especially if it is considered "end stage chronic illness", proves that modern western medicine has failed to offer a curative treatment for such an illness. "End stage chronic illness" often causes progressive failure of the affected organ, to the extent that it seriously affects the function or even endangers the life of the sick person. Replacement of the affected organ is considered, either in the form of transplantation, i.e. replacement with a living organ, or replacement with a mechanical artificial organ. Replacement with a mechanical artificial organ could be either temporary-like artificial kidney for temporary intermittent hemo-dialysis, temporary pacemakers or temporary cardiac assist devices; or permanent-like permanent pacemakers, total mechanical heart, or total mechanical joints. Whether it is transplantation or total mechanical replacement, the situation remains the same: a curative treatment for the affected organ is not available.

To my knowledge, there are now several patients who were thought to need heart transplantation for cardiomyopathy or a combination of cardiomyopathy and atherosclerotic heart disease; or liver transplantation for hepatic cirrhosis; or who had progressive renal failure and were projected in a year or less to require hemodialysis and/or kidney transplantation. I know these patients to be in a stable and progressively improving condition for one or several years, and not requiring the transplantation once thought to be needed. However, it is an example of what could be an "equally effective, therapeutic modality that is simpler, safer and more cost effective." Even conventional modern western approaches may offer alternative options to transplantation-for example, combinations of partial temporary mechanical support combined with either pharmacologic or natural conservative management, and so on. However, if none of these options is available for a given patient, then and only them, transplantation should be considered a "fulfillment of Islamic duty.
Having overcome this hurdle, there are several other hurdles to overcome. The first one is that organ donation not result in any harm to the donor. For a successful outcome of transplantation, the transplanted organ has to be living, or at least viable. This could be the case of a double organ-i.e. a kidney-from a living donor who is a good surgical candidate for the nephrectomy, meaning having a healthy second kidney, and being physiologically fit for the surgery. This situation is very limited (a donor who is a member of the immediate family of the recipient), and will seriously limit the availability of organs to be transplanted. If we could have viable organs from dead donors, this would greatly improve the availability of single organs (like heart and liver) as well as double organs. The problem we face here is that for an organ to be viable, it has to have active circulation and oxygenation. But if we wait until the donor is dead according to the traditional criteria for death-i.e., absence of pulse and respirationthe organs are no longer viable. This dilemma was overcome by accepting brain stem death as an adequate criterion for death. This means that a person may be considered dead if his or her brain stem death is ascertained, even while the heart is still beating and respiration is artificially maintained. This bran stem death as the criterion for the donor's death has been accepted by the great majority of Muslim scholars who deal with the issue of transplantations, whether they are medical experts or Muslim jurists. This was the consensus of the participants of several specialized workshops and seminars that were held in various parts of the Muslim world like Kuwait, Saudi Arabia, Egypt, Jordan and others $[9,10]$. These specialized workshops and seminars included a large number of experts from various schools of thought over twenty Muslim jurists and an equal number of Muslim medical experts. Until two weeks ago, I thought that this issue was finalized and settled among the expertsMuslim and non-Muslim-over ten years ago. However, less than two weeks ago, I realized that I was not quite correct in my assumption. I realized that there are still some people who are thought to be experts, or who give the impression of being experts, who feel that brain stem death is not a valid criterion for death, who feel that transplant surgeons kill donors by removing their vital organs while they (the donors) are still alive and that organ transplantation must be banned and prohibited altogether [11-13]. This opposition is created by these individuals is greatly magnified by the mass media. The physicians behind the movement against organ transplantation use several medical references from European and American literature to support their views. Upon careful review of their listed references, it becomes obvious that these references are of two types: 1 . sporadic reports of isolated cases where brain stem death was not adequately verified and not definitely ascertained; then it was later discovered that it was not truly brain stem death; of 2 . Sporadic reports of isolated cases where some pathologies of the nervous system were misdiagnosed and initially mistaken for brain death and where it was later discovered that they were not truly cases of brain death. In other words, the few cases reported were sporadic cases of human error, either in the form of misdiagnosis or inadequate verification due to improper testing. This still does not change the fact that if and when brainstem death is ascertained and confirmed, it is an adequate proof of death. As to the references from mass-media, these proved to be reports of criminal cases where people-patients, children, or others-were killed, abused or kidnapped in order to obtain some of their organs for commercial purposes. After all, these are crimes and crimes are wrong. These cases however do not prove or disprove that brain stem death is or is not a criterion for death. This means that all these sensational reports in the mass media are totally irrelevant. So much for the argument against brain stem death. 
Another reason for the prohibition of the transfer and transplantation of human organs listed in the book written by the above mentioned professor of anesthesiology from Cairo, is the statement that taking any organ from a living donor or even from a dead donor is absolutely prohibited because the body of the donor belongs to God and not to the donor, living or dead, and therefore the donor has no right to give his/her body or any part thereof, neither by selling, or gift giving, or in any other way. This is a statement which is partially true but does not have any logic and does not make any sense. It is true that everything belongs to God, I mean everything, the donor's blood, the donor's milk (in the case of a nursing mother), everything! Still, the donor has the right to give his knowledge, his time, his money, his blood, her milk (in the case of a nursing mother), without being accused of transgressing against the ownership of God. As a matter of fact, it is considered a virtue and a good deed to give of what you have for a good cause. So much for the ownership argument.

In addition to the irritating argument mentioned above, the promoter of the movement against organ transplantation appears to be unaware of some of the rules of fundamentals of jurisprudence. The worst scenario about organ transplantation-in his opinion-or it could be lawful, as in the opinion of the majority of experts. For him to make the statement that transfer and transplantation of organs is "absolutely prohibited" indicates his unawareness of the rule of fundamentals of jurisprudence which says that "prohibiting the lawful is worse than allowing the unlawful": for example, to say drinking water is haram is worse that saying drinking wine is halal.

Let us move on to some other easier issues: Organ donation is done with the free will and full approval of the donor, or-in the case of an unconscious donor, or an organ donation taken from a cadaver-with the approval of the next of kin or legal guardian. A human being, donor or recipient, is a free individual. Free will and freedom of choice are God-given rights. These God-given rights cannot be imposed on someone without his or her full approval, or-if he/she is not in a position to make such a decision-then without the approval of the next of kin or legal guardian.

Another issue is that the donated organ is not sold. This statement is based on the sanctity of the human body, and the ownership by God the Almighty. That is why the majority of experts feel that human organs should not be used for commercial gain except under pressing circumstances. However, this issue is controversial and some experts allow it although the majority does not. Discussion of this issue will not be given here due to the limitation of time.

An important issue that must be briefly mentioned is that the transplantation of active reproductive organs is categorically forbidden in Islam. That is because such transplantation would lead to the violation of basic Islamic rules governing marriage, reproduction and inheritance.

Lastly, the question of Muslims donating organs to no-Muslims and vice versa needs to be addressed. I feel that this should be allowed if we consider the whole issue of organ donation as an act of human mercy, keeping in mind that the main-if not only-purpose of the mission of prophet Muhammad, peace be upon him, is to be a mercy for mankind. "We have not sent you but as a mercy for the worlds.

To summarize we can say that from the viewpoint of Islam, organ donation and transplantation is an acceptable therapeutic option provided the following criteria are fulfilled:
1. There is no other equally effective therapeutic modality available that is simpler and safer and /or more cost effective.

2. The organ donation does not result in any harm to the donor.

3. The organ donation is done with the free will and full approval of the donor, or-in the case of an unconscious donor or an organ donation taken from a cadaver-with the approval of the next of kin or legal guardian.

4. In the case of donation of a single organ upon which the life of the donor depends, e.g., the heart or liver, the organ may not be removed from the donor until the donor's brain stem death is ascertained.

5. The donated organ is not sold.

6. If the transaction results in material or monetary gain to the donor or to the donor's family, the gain must not be in the form of a price, but the donor or his/her family may accept a gift as a token of appreciation since the donated organ is considered a gift to the recipient.

7. The transplantation of active reproductive organs is categorically forbidden.

8. The basic rule governing the entire transaction is that organ transplantation is considered a humanitarian act of mercy accomplished with the free will and approval of all parties involved under no pressure, coercion, or injustice.

\section{Additional Notes}

By word "transaction" I mean some voluntary compensation to donor as a gift in appreciation of his/her charity.

Definition of death has evolved in Islam now to accept "brain stem death" while the old imams with little knowledge of medicine still use old definition of respiratory death as death.

Contemporary educated Muslim physicians and scholars have accepted donation and transplantation of live organs or part of it as gift to save life and enhance the quality of life of the recipient as long as there is no medical harm to the donor. Included in the category are kidney, liver and bone marrow.

Though some conservative imam may object to receiving heart or blood transfusion from an unbeliever, I as Muslim physician do not. The blood and life of all humans is pure and sacred to me.

Organ retrieval from a brain dead person is allowed with permission of the family. The issue is the desecration of dead body and not the use of usable organs after death as there is urgency to return the body to earth. Muslims do not have belief that have to present their intact body to God in the life hereafter.

\section{References}

1. Quran 5:32.

2. Quran 36:79.

3. Ibn Majah, Ahmad Ibn Hanbal, Abu Dawood: Hadith Collections of Termithy.

4. Quran 5:2

5. Al-Muattaa, Ahmad Ibn Hanbal: Hadith Collections of Ibn Majah

6. Abu Dawood, Termithy: Hadith Collections of Bukhari, Muslim.

7. Quran 7: 31.

8. Quran 17:27. 
Citation: Athar S (2015) A Gift of Life: An Islamic Perspective in Organ Donation and Transplantation . J Transplant Technol Res 5: 146. doi: 10.4172/2161-0991.1000146

Page 4 of 4

9. Second Symposium on Islam and Current Medical Concerns: Human life, its beginning and end from Islamic perspective, organized by the Islamic Organization for Medical Sciences, Kuwait, January 1985. Proceedings of symposium. Publications of Islamic Organization of Medical Sciences, Center of Islamic medicine, Kuwait.

10. Third Symposium on Islam and Current Medical Concerns: The Islamic Vision of Some Medical Practices, organized by the Islamic Organization for Medical Sciences, Kuwait, April 1987. Proceedings of the symposium. Publications of Islamic Organization of Medical Sciences, Center of Islamic Medicine, Kuwait.
11. Lotfi, Safwat $\mathrm{H}$ : Reasons for Prohibition of the Transfer and Transplantation of Human Organs. Publisher unlisted. Filing number 92/77662. Anesthesia Department, Cairo. University School of Medicine, Cairo, Egypt.

12. Lotfi, Safwat H.: Definition of death in Islam. Publishing information unlisted. Anesthesia Department, Cairo University School of Medicine, Cairo, Egypt.

13. Quran 21:07. 